\title{
Analisis Manajemen Risiko Pada Proyek Pembangunan Ruas Jalan Baru Waebetu - Tarawaja
}

\author{
Fransiska Moi", I.G.A. Neny Purnawirati \\ Jurusan Teknik Sipil, Politeknik Negeri Bali \\ *Correspondence email: inmoi1909@pnb.ac.id, nenypurnawirati@pnb.ac.id
}

\begin{abstract}
Abstrak. Ruas Jalan yng menghubungkan antara Kota Bajawa dan Bandar Udara Turelelo Soa merupakan urat nadi transportasi penting di Kabupaten Ngada. Manajemen risiko adalah proses sistematik dari perencanaan, identifikasi, analisis, pemberian respon, dan pengawasan dari risiko-risiko proyek. Manajemen risiko melibatkan proses-proses, alat-alat, dan teknik-teknik yang akan membantu manajer memaksimalkan kemungkinan dan konsekuensi dari kejadian-kejadian positif dan meminimalkan kemungkinan dan konsekuensi dari kejadian-kejadian negatif. Penelitian ini bertujuan untuk mendapatkan risiko dominan serta dapat mengetahui tindakan yang tepat untuk menangani risiko tersebut dimana hal ini dilakukan untuk meminimalisir terjadinya risiko yang berpengaruh terhadap biaya dan waktu. Metode pada penelitian ini menggunakan metode survei. Analisis dimulai dari identifikasi risiko melalui survey, wawancara, obeservasi dan studi literatur, kemudian dilakukan penyebaran kuesioner kepada responden atau tenaga ahli pada proyek pembangunan jalan baru pada ruas jalan Waebetu - Tarawaja. Kemudian dilakukan analisis risiko, untuk mengetahui risiko-risiko dominan. Risiko dominan dikendalikan melalui tindakan mitigasi dan pengalikasian risiko terhadap pihak-pihak yang terlibat langsung pada proyek konstruksi seperti Owner, dan Kontraktor. Analisis yang digunakan dalam penelitian ini adalah analisis kualitatif. Hasil penelitian menunjukkan 49 risiko yang teridentifikasi pada pelaksanaan proyek yang bersumber dari risiko perencanaan sebesar 5\%, risiko teknis sebesar $27 \%$, risiko proyek sebesar $24 \%$, risiko ekonomi sebesar $11 \%$, risiko manusia sebesar $13 \%$, risiko politik sebesar $7 \%$, risiko lingkungan sebesar $1 \%$ dan risiko alam sebesar $12 \%$. Penerapan manajemen risiko dalam proyek Pembangunan Jalan Baru pada Ruas Jalan Waebetu - Tarawaja perlu menjadi bagian penting dalam proses perencanaan/manajemen proyek, karena dapat menilai risiko secara luas dan memudahkan dalam mempersiapkan strategi penanganannya.
\end{abstract}

Kata Kunci: Manajemen Risiko, Identifikasi Risiko, Mitigasi Risiko, Kepemilikan Risiko, Respon Risiko

\section{PENDAHULUAN}

Ruas Jalan Waebetu - Tarawaja merupakan ruas jalan dengan tipe 2 lajur 2 arah tidak terbagi yang menghubungkan kota Bajawa dan Soa. Wilayah ini merupakan wilayah yang berada dalam cakupan jalur penghubung dimana kota Bajawa merupakan ibu kota Kabupaten Ngada dan Soa merupakan wilayah lokasi Bandar Udara Turelelo. Oleh karena itu, perlu diadakannya akses yang lebih cepat untuk menghubungkan kedua wilayah tersebut dengan membangun ruas Jalan Waebetu - Tarawaja. Proyek Pembangunan Ruas Jalan Waebetu - Tarawaja merupakan proyek dengan tingkat resiko yang sulit diprediksi, sehingga diperlukan analisis manajemen risiko yang mendalam.

Manajemen risiko adalah proses sistematik dari perencanaan, identifikasi, analisis, pemberian respon, dan pengawasan dari risiko-risiko proyek. Maka pada proyek konstruksi jalan raya tidak akan pernah terhindar dari risiko dalam skala kecil maupun skala besar. Semakin kecil potensi risiko yang ditimbulkan maka akan semakin menguntungkan proyek baik dari segi biaya maupun dari segi pelaksanaan pembangunannya. Apabila skala proyek semakin besar maka besar pula potensi risiko yang ditimbulkan yang bila tidak ditangani dengan benar akan menghambat pelaksanaan proyek.

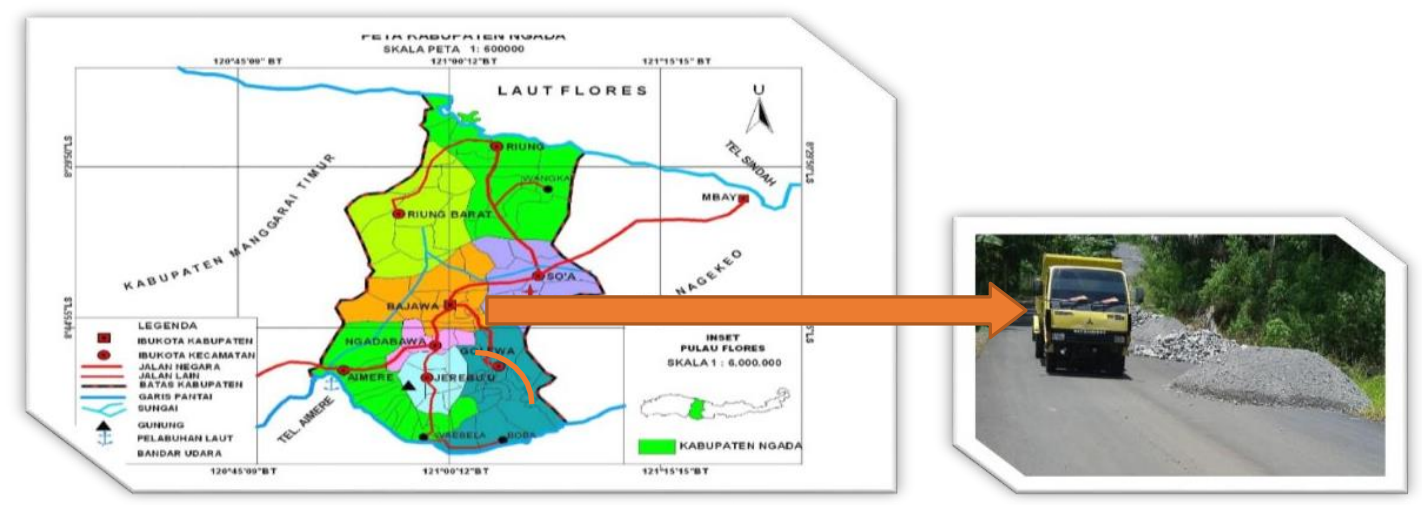

Gambar 1. Ruas Jalan Tarawaja - Waebetu

Sumber : Lokasi Pembangunan Ruas Jalan Waebetu Tarawaja, 2021 
Tujuan dari rancangan penelitian ini adalah untuk menentukan parameter data yang akan disurvai dan juga menentukan metode yang diperlukan untuk mengumpulkan data dimaksud. Metode penelitian ini menggunakan metode deskriptif kualitatif dimana metode ini digunakan untuk meyelidiki obyek yang tidak dapat diukur dengan angka-angka ataupun ukuran lain yang bersifat eksak.

Menurut Flanagan, R. dan Norman, G. 1993 mengenai risk management, risiko-risiko dalam proyek konstruksi adalah :

a. Penyelesaian yang gagal sesuai desain yang telah ditentukan/penetapan waktu konstruksi

b. Kegagalan untuk memperoleh gambar perencanaan, detail perencanaan/izin dengan waktu yang tersedia.

c. Kondisi tanah yang tak terduga

d. Cuaca yang sangat buruk.

e. Pemogokan tenaga kerja.

f. Kenaikan harga yang tidak terduga untuk tenaga kerja dan bahan.

g. Kecelakaan yang terjadi dilokasi yang menyebabkan luka.

h. Kerusakan yang terjadi pada struktur akibat cara kerja yang jelek.

i. Kejadian tidak terduga (banjir, gempa bumi, dan lain-lain)

j. Klaim dari kontraktor akibat kehilangan dan biaya akibat keterlambatan produksi karena detail desain oleh tim desain.

k. Kegagalan dalam penyelesaian proyek dengan budget yang telah ditetapkan

Sumber-sumber risiko yang terdapat dalam kuesioner penelitian pada proyek Pembangunan Ruas Jalan Waebetu - Tarawaja adalah sebagai berikut :
a. Perencanaan
b. Teknis
c. Proyek
d. Ekonomi
e. Manusia
f. Politik
g. Lingkungan
h. Alami

\section{METODE}

\section{Waktu dan Lokasi Penelitian}

Lokasi penelitian dilaksanakan pada Ruas Jalan Waebetu - Tarawaja, Desa Soa, Kecamatan Soa. Dimana pada proyek tersebut dibangun jalan dan 8 jembatan. Waktu penelitian dimulai pada Bulan Oktober 2020.

\section{Jenis dan Sumber Data}

Data primer adalah data-data berupa sejumlah keterangan atau fakta yang penulis peroleh langsung dari tempat penelitian, dalam hal ini data dapatkan melalui observasi lapangan dan menggunakan kuesioner. Kuesioner merupakan teknik pengumpulan data yang dilakukan dengan cara memberi seperangkat pertanyaan tertulis kepada responden untuk dijawabnya. Sedangkan data sekunder adalah data-data yang diperoleh secara tidak langsung. Dimana pada studi kasus ini data-data yang diperlukan seperti dokumen-dokumen proyek, jurnal, literatur, dan gambar. 
Fransiska Moi dan I.G.A. Neny Purnawirati, Analisis Manajemen Risiko Pada Proyek Pembangunan Ruas Jalan Baru Waebetu - Tarawaja

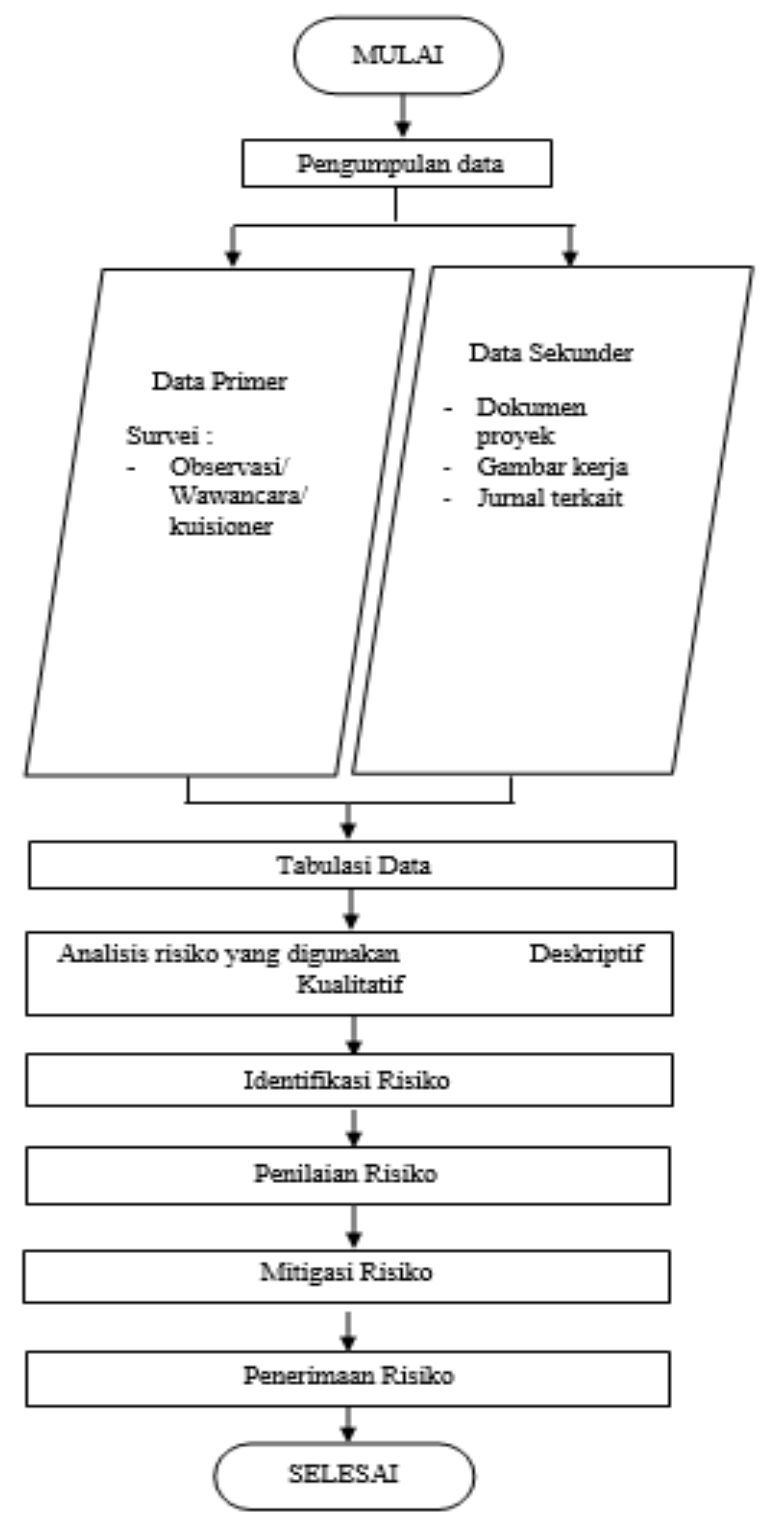

Gambar 2. Bagan Alir Penelitian

\section{HASIL DAN PEMBAHASAN \\ Karakteristik Proyek}

Pada proyek Pembangunan Ruas Jalan Waebetu - Tarawaja di Desa Soa Kecamatan Soa Kabupaten Ngada ini merupakan proyek milik Dinas PUPR Kabupaten Ngada dengan Kontraktor Pelaksana yakni PT. SUKSES KARYA INOVATIF dengan sumber dana APBD II Tahun Anggaran 2016 sebesar Rp.3.995.599.000,00 (inc PPN).

\section{Identifikasi Risiko}

Berikut sumber-sumber resiko yang terdapat dalam kuesioner penelitian pada proyek Pembangunan Ruas Jalan Waebetu - Tarawaja

Tabel 1. Sumber-Sumber Risiko

\begin{tabular}{clc}
\hline No & \multicolumn{1}{c}{ Identifikasi Risiko } & Sumber Risiko \\
\hline 1 & $\begin{array}{l}\text { Dokumen kontrak yang tidak mengatur secara detail tentang penanggulangan risiko } \\
\text { investasi }\end{array}$ & Perencanaan (Planning) \\
2 & $\begin{array}{l}\text { Gambar saat tender tidak lengkap } \\
3\end{array}$ & Tidak adanya persyaratan analisis risiko dalam dokumen penawaran \\
4 & Klausul-klausul kontrak yang kurang lengkap & Teknis (Tehnical) \\
\hline 5 & Data yang digunakan dalam teknis studi kelayakan kurang (technical akurat) & \\
6 & Desain yang belum final dan data pendukung yang belum lengkap & \\
7 & Perencanaan yang kurang tepat &
\end{tabular}


$8 \quad$ Pemahaman desain yang kurang baik

9 Detail BOQ yang tidak lengkap

10 Kinerja peralatan yang digunakan kurang baik atau produktifitasnya tidak sesuai dengan yang direncanakan

11 Kerusakan peralatan (alat berat) mengakibatkan keterlambatan

12 Kurangnya peralatan dalam mendukung pekerjaan di lapangan

13 Jumlah peralatan tidak memadai/tidak sesuai dengan produktifitas yang ditentukan

14 Penggunaan fasilitas peralatan (attachment) tidak sesuai dengan panduan

15 Terjadinya kerusakan jalan disekitar proyek akibat dilewati dump truk pengangkut material proyek

16 Terganggunya proses mobilisasi akibat sulitnya medan mobilisasi

17 Lahan yang dibutuhkan untuk pembangunan pekerjaan tidak sepenuhnya dapat disediakan oleh pemerintah

18 Proses ganti rugi sulit dilaksanakan dan harga kompensasi yang terjadi diatas perkiraan anggaran yang disediakan

19 Adanya penolakan warga terhadap pembebasan lahan

20 Proses pembebasan lahan yang berbenturan dengan instansi lain (Kementerian Kehutanan)

21 Keterlambatan/kerugian akibat ketersediaan material yang menyebabkan pekerjaan terlambat

22 Kehilangan material dan alat-alat pekerjaan

Proyek (Project)

23 Kualitas material yang kurang baik atau rendah yang tidak sesuai dengan spek yang telah ditentukan

24 Kenaikan harga material

25 Tempat penyimpanan material yang tidak layak mengakibatkan material rusak

26 Tidak sesuainya metode pemeliharaan yang diterapkan

27 Masalah keuangan pada saat masa pemeliharaan

28 Kedatangan material pemeliharaan jalan yang terlambat

29 Tidak dilakukan pemeliharaan pada komponen jalan dengan baik

30 Risiko yang muncul akibat ketidakpastian dalam hal kontinuitas sumber dana pembiayaan

31 Kenaikan harga lahan yang dibebaskan saat pelaksanaan pekerjaan berlangsung

32 Terjadi pekerjaan tambahan dengan harga timpang

33 Terjadi keterlambatan jadwal proyek yang berpengaruh pada biaya proyek

34 Banyaknya calo atau perantara dalam pembebasan tanah menimbulkan ketidakpastian harga dan harga pembebasan tanah menjadi lebih mahal

35 Adanya ketidakpastian dalam tingkat suku bunga pinjaman yang harus dibayarkan selama masa konstruksi

36 Tenaga kerja tidak sesuai dengan persyaratan kompetensi

$37 \quad$ Ketidakcakapan tenaga kerja mempengaruhi kualitas

38 Kerja sama tim yang kurang dalam bekerja

39 Adanya pekerja atau pelaksana yang tidak jujur sehingga menimbulkan risiko

Manusia (human)

kerugian akibat kehilangan atau penambahan biaya

$40 \quad$ Kemungkinan terjadinya mogok akibat ketidakpastian pekerja proyek

41 Adanya pergantian pejabat daerah yang berakibat pada pengambilan keputusan

42 Jadwal pelaksanaan pekerjaan yang bersamaan dengan pilkada

43 Kelemahan dalam penyelesaian perselisihan antara pihak - pihak tertentu

Ekonomi (Ekonomic)

$44 \quad$ Koordinasi antar fungsi pada organisasi proyek yang kurang

45 Adanya perubahan undang-undang

46 Terjadinya pencemaran lingkungan udara dan kebisingan yang menggangu selama pelaksanaan pekerjaan shortcut berlangsung

47 Cuaca yang tidak menentu mengakibatkan terhambatnya suatu pekerjaan

48 Kondisi geologi tanah (tingkat kekerasan tanah yang tidak standar

49 Cuaca kurang baik

Sumber : Data Olahan (2021) 
Fransiska Moi dan I.G.A. Neny Purnawirati, Analisis Manajemen Risiko Pada Proyek Pembangunan Ruas Jalan Baru Waebetu - Tarawaja

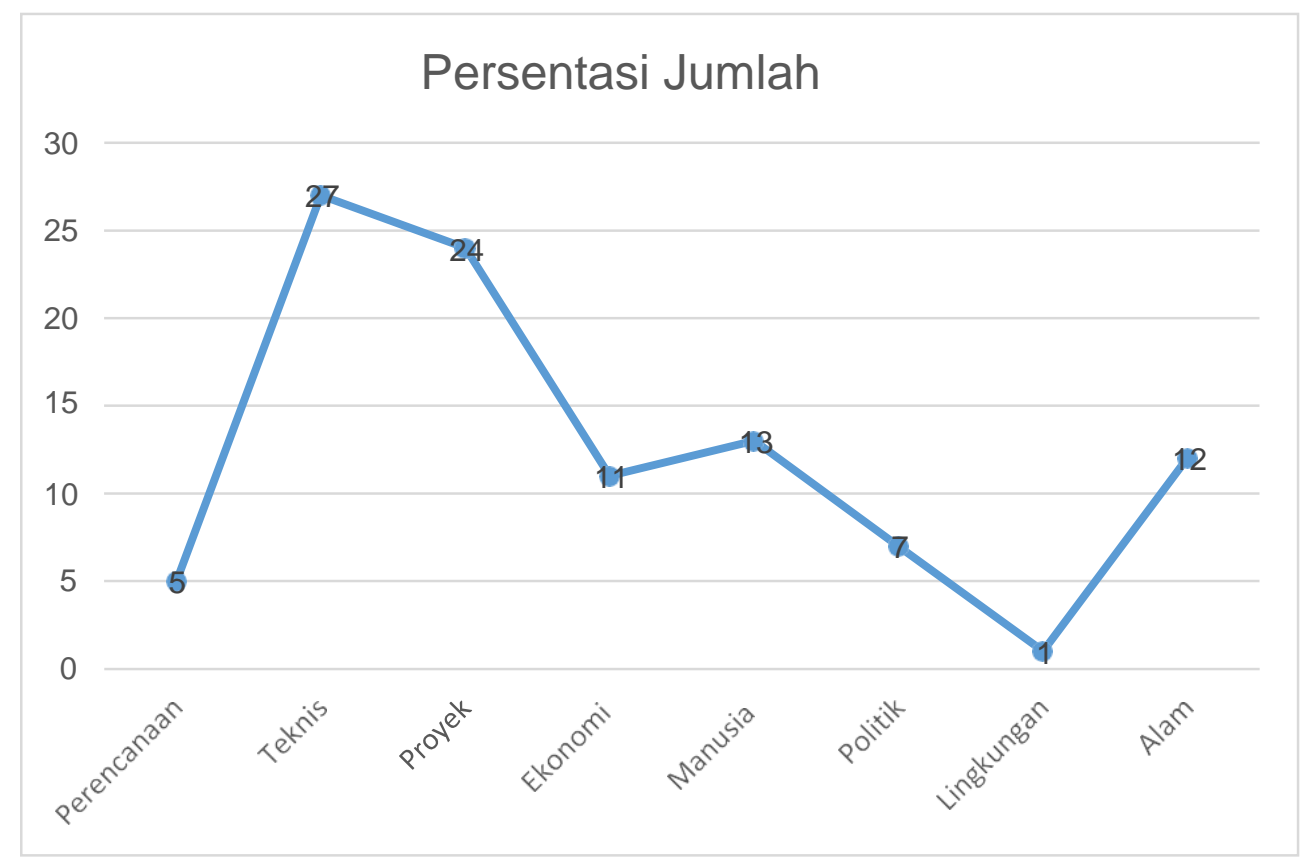

Sumber : Data Olahan (2021)

Gambar 3. Identifikasi Berdasarkan Sumber Risiko

Dari gambar diatas dapat dilihat faktor risiko penyebab keterlambatan proyek konstruksi yang didapat dari hasil wawancara pada obyek penelitian. Faktor terbesar penyebab keterlambatan proyek adalah faktor teknis sebesar $27 \%$, diikuti oleh faktor proyek sebesar $24 \%$. Sedangkan faktor terkecil disebabkan oleh faktor lingkungan sebesar $1 \%$.

\section{Penilaian Risiko}

Penilaian risiko berdasarkan atas data primer dan sekunder yang merupakan data hasil wawancara, kuisioner dan pengamatan langsung di lapangan mengenai risiko-risiko yang terjadi pada proyek Pembangunan Ruas Jalan Waebetu - Tarawaja. Risiko diformulasikan sebagai fungsi dari kemungkinan terjadi (likelihood) dan dampak negatif (impact). Atau indeks risiko $=$ Probabilitas (Likelihood) $X$ Dampak ( Impact). Berikut ini adalalah tabel hasil perhitungan indeks risiko:

Tabel 2. Hasil Risiko Berdasarkan Perhitungan

\begin{tabular}{llcccc}
\hline No & Identifikasi Risiko & P & I & PxI & Kategori Risiko \\
\hline 19 & Adanya penolakan warga terhadap pembebasan lahan & 3 & 4 & 12 & H \\
11 & Kerusakan peralatan (alat berat) mengakibatkan keterlambatan & 3 & 4 & 12 & H \\
33 & $\begin{array}{l}\text { Terjadi keterlambatan jadwal proyek yang berpengaruh pada biaya } \\
\text { proyek }\end{array}$ & 3 & 3 & 9 & M \\
47 & $\begin{array}{l}\text { Cuaca yang tidak menentu mengakibatkan terhambatnya suatu } \\
\text { pekerjaan }\end{array}$ & 3 & 3 & 9 & $\mathrm{M}$ \\
37 & Ketidakcakapan tenaga kerja mempengaruhi kualitas & 3 & 3 & 9 & $\mathrm{M}$ \\
48 & Kondisi geologi tanah (tingkat kekerasan tanah yang tidak standar) & 3 & 3 & 9 & $\mathrm{M}$ \\
\hline
\end{tabular}

Sumber : Data Olahan (2021)

\section{Pembahasan}

Dari hasil analisa didapatkan faktor risiko dominan adalah adanya penolakan warga terhadap pembebasan lahan dan kerusakan peralatan (alat berat) mengakibatkan keterlambatan sedangkan untuk risiko medium adalah terjadi keterlambatan jadwal proyek yang berpengaruh pada biaya proyek, Cuaca yang tidak menentu mengakibatkan terhambatnya suatu pekerjaan, ketidakcakapan tenaga kerja mempengaruhi kualitas, dan kondisi geologi tanah (tingkat kekerasan tanah yang tidak standar).

\section{Mitigasi Risiko}

Berdasarkan risiko-risiko yang telah didaptkan melalui perhitungan,

\section{Risiko High}

a. Kontraktor harus melakukan pendekatan dengan pimpinan tertinggi di wilayah desa (kepala desa) terlebih dahulu sebelum pekerjaan dimulai 
b. Perlu pengaturan alat berat yang lebih efektif, alat berat harus memiliki standart pengujian berkala

2. Risiko Medium

a. Kontraktor harus membuat perkiraan jadwal proyek dan membuat alternatif percepatan kerja proyek

b. Kontraktor harus membuat laporan cuaca berdasarkan keadaan di lapangan dilengkapi dengan data BMKG dan menemukan solusi bersama owner untuk mengatasi permasalahan yang ada

c. Pihak owner harus memastikan operator alat berat harus memiliki sertifikat keahlian dan surat ijin operasi

d. Kontraktor harus selalu memastikan kondisi alat berat agar tetap produktif

\section{Kepemilikan Risiko}

Pada risiko mayor (High) kepemilikan risiko ditanggung oleh kontraktor dimana risiko ini terjadi pada tahap sebelum proyek pembangunan jalan berjalan dan pada saat proyek pembangunan jalan sedang berjalan. Sedangkan pada risiko sedang (Medium) risiko ditanggung oleh PU (Owner) untuk memastikan operator alat berat harus memiliki sertifikat keahlian dan surat ijin operasi dan ditangung oleh kontraktor dimana ontraktor harus membuat perkiraan jadwal proyek dan membuat alternatif percepatan kerja proyek, kontraktor harus membuat laporan cuaca berdasarkan keadaan di lapangan dilengkapi dengan data BMKG dan menemukan solusi bersama owner untuk mengatasi permasalahan yang ada.

\section{SIMPULAN}

Berdasarkan hasil penelitian dan hasil analisis yang telah dilakukan pada proyek Pembangunan Ruas Jalan Waebetu - Tarawaja adalah sebagai berikut:

a. Dari hasil analisis didapatkan 2 risko High yang menimbulkan dampak yang signifikan yakni adanya penolakan warga terhadap pembebasan lahan dan kerusakan peralatan (alat berat) mengakibatkan keterlambatan. Sedangkan risiko sedang (Medium) yang kemungkinan besar terjadi dapat menimbulkan dampak yang signifikan.

b. Kepemilikan risiko pada risiko mayor ditanggung oleh kontraktor dimana risiko ini terjadi pada tahap sebelum proyek pembangunan jalan berjalan dan pada saat proyek pembangunan sedang berjalan

\section{Saran}

Berdasarkan hasil penelitian dan kesimpulan, maka dapat disarankan sebagai berikut:

a. Untuk menghindari atau memperkecil risiko dalam proyek kontraktor harus melakukan pendekatan terlebih dahulu kepada pimpinan wilayah tertinggi sebelum proyek berjalan, karena masalah pembebasan lahan sangat berpengaruh terhadap faktor risiko lain. Selain itu kontraktor harus mamperhatikan kualitas alat berat.

b. Bagi peneliti lain yang ingin melakukan penelitian mengenai manajemen risiko dan tingkat risiko proyek dapat juga menggunakan metode lain dengan cara kuantitatif agar didapatkan hasil yang lebih akurat lagi.

\section{DAFTAR PUSTAKA}

Adi Setiawam, Eko Walujodjati, Ida Farida. 2014. Analisis Manajemen Risiko Pada Proyek Pembangunan Jalan Tol Cismdawu”,: Vol. 11 Sekolah Tinggi Teknologi Garut

Bekti Siwi Aningrum. 2012. "Identifikasi dan analisis risiko dalam masa pemeliharaan proyek pada proyek konstruksi di Kota Surakarta”, Skripsi. Universitas Sebelas Maret Surakarta.

Flanagan, R. dan Norman, G. 1993, Risk management and Construction, Blackwell science Ltd.Oxford.

Soeharto, Imam. 2001. Manajemen Proyek. Jilid 1. Edisi Penerbit Erlangga, Jakarta.

Pusat Materi Kuliah. 2011 “Cara Mengidentifikasi Risiko” Kamis, Pusat Materi Kuliah

Hanafi, M. 2009. Manajemen Risiko. UPP STIM YKPN. Yogyakarta

Soemarwoto, Otto (2009). “Analisis Mengenai Dampak Lingkungan”. Gajah Mada Univercity Press. Yogyakarta

Sugiyono.2005. Metode Penelitian Kuantitatif, Kualitatif dan R\&D. Bandung : Afabeta 